Original Research Article

\title{
Study on the antiemetic property of methanolic stem extract of Swertia chirata using chick emesis model
}

\author{
Pranjal Kr. Medhi*, Kalpana Gohain
}

Department of Pharmacology, Basic Sciences Building, Assam Medical College and Hospital, Dibrugarh-786002, Assam, India

Received: 31 December 2018 Accepted: 17 January 2019

\section{*Correspondence to: Dr. Pranjal Kr. Medhi, Email: drpranjalmedhi18@ gmail.com}

Copyright: () the author(s), publisher and licensee Medip Academy. This is an openaccess article distributed under the terms of the Creative Commons Attribution NonCommercial License, which permits unrestricted noncommercial use, distribution, and reproduction in any medium, provided the original work is properly cited.

\begin{abstract}
Background: Swertia chirata has been an important herb known for centuries for its various medicinal uses and bitter taste. The stem of the plant is used as a traditional medicine in an array of diseases including the treatment of vomiting. Therefore, the study was undertaken to explore the possible antiemetic property of methanolic extract of its stems by using chick emesis model.

Methods: 25 male chicks of four days old weighing 25 to 35 grams were fed with copper sulfate anhydride at $50 \mathrm{mg} / \mathrm{kg}$ body weight to induce emesis. The chicks were grouped into 5 with each group bearing 5 chicks $(n=5)$. Group I (control) received $10 \mathrm{ml} / \mathrm{kg}$ normal saline; group II (standard) received $150 \mathrm{mg} / \mathrm{kg}$ chlorpromazine; group III (experimental-1), group IV (experimental-2) and group V (experimental-3) received 50, 100 and $150 \mathrm{mg} / \mathrm{kg}$ respectively of the extract. All doses are given intraperitoneally. Assessment of antiemetic activity was done by calculating the percentage of inhibition of the number of retches in the chicks.

Results: All the three doses of the extract showed antiemetic activity. The dose of $50 \mathrm{mg} / \mathrm{kg}$ showed activity comparable to chlorpromazine, while dose of 100 $\mathrm{mg} / \mathrm{kg}$ and $150 \mathrm{mg} / \mathrm{kg}$ showed greater activity than chlorpromazine. Highest antiemetic activity (79.26\% inhibition) was shown by a dose of $150 \mathrm{mg} / \mathrm{kg}$ and lowest (42.22\% inhibition) by $50 \mathrm{mg} / \mathrm{kg}$.

Conclusions: Methanolic extract from the stems of Swertia chirata has excellent anti-emetic property which can be further investigated for development of potential antiemetic medicines.
\end{abstract}

Keywords: Antiemetic, Chick emesis model, Chlorpromazine, Swertia chirata

\section{INTRODUCTION}

Vomiting is one of our protective mechanisms by which we get rid of the unwanted, toxic or harmful substances either ingested or produced within the body. Despite being so, it often becomes very troublesome and stressful for the patients especially during cancer chemotherapy, radiation therapy, in the post-operative period and in the first trimester of pregnancy. Apart from being uncomfortable, vomiting if it becomes severe can lead to complications like dehydration, electrolyte abnormalities, undernutrition, weight loss and rarely esophageal tear, either partial (Mallory-Weiss syndrome) or complete (Boerhaave syndrome) etc. ${ }^{1}$ There are many antiemetic drugs available currently in the market. Most of them have overlapping mechanisms of action and are not safe in pregnancy during the first three months. Not only the various adverse effects, they also lack effectiveness as compared to the wide spectrum of their antiemetic actions. Keeping this objective in view, search was being made in various scientific literatures for the indigenous plants claimed to have anti-emetic property. Swertia chirata was found out to be one such plant that is being used for a long time in traditional medicine to treat vomiting. ${ }^{2,3}$ Not only that, it is used for the treatment of various diseases like anemia, bronchial asthma, constipation, dyspepsia, skin diseases, worm infestation, epilepsy, ulcers, scanty urine, hepatitis, 
fever, malaria, hypertension, diabetes, certain types of mental disorders etc. ${ }^{2,4}$

Swertia chirata, known as "Anaryatikta, Bhunimba or Chiratitka" in Sanskrit is an annual or biennial herb with a height of $0.6-1.5 \mathrm{~m}$ with erect $2-3 \mathrm{ft}$ long stems in orangebrown or purplish color with large continuous yellowish pith; stalkless leaves, simple tetramerous green-yellow flower and simple, yellowish, $1 / 2$ inch thick roots.

The herb grows at high altitudes of sub-temperate zones of the Himalayas between 1200 to 2100meters altitude extending from Kashmir to Bhutan on their moist, shady slopes, and in the Khasi hills of Meghalaya. The herb contains several important phytoconstituents with pharmacological properties. Some of those are: amarogentin (bitterest substance discovered till date) with topoisomerase inhibiting, chemo-preventive and antileishmanial properties; amaroswerin with gastroprotective properties; gentianine with anti-inflammatory, anesthetic, antihistaminic, antipsychotic, anticonvulsant and diuretic properties; swerchirin with antimalarial and pro-haematopoietic properties and so on. ${ }^{2,4}$ Careful and thorough literature searches have shown that no study has yet been done by anyone to explore the possible antiemetic property of Swertia chirata. Therefore, the present study was conducted to find out the possible anti-emetic property of the methanolic extract from the stems of the herb.

\section{METHODS}

The study was conducted in the department of pharmacology, Assam Medical College, Dibrugarh during the period from November 2017 to February 2018.

\section{Materials}

Approximately $1 \mathrm{~kg}$ of fresh and uninfected stems of Swertia chirata were collected from a local vendor in Dibrugarh during the month of November 2017. The plant was authenticated in the Department of Life Sciences, Dibrugarh University, Assam, India.

\section{Drugs and chemicals}

Methanol 100\% (analytical grade), Dimethyl sulfoxide (DMSO), Tween 80 (polyoxy-ethylene sorbitan monooleate) and copper sulfate anhydride were purchased from Research-Lab Fine Chem Industries Pvt. Ltd, Mumbai (India). Chlorpromazine was purchased from Sun Pharmaceuticals Industries Ltd, Mumbai (India). Normal saline was taken from department's laboratory itself.

\section{Experimental animal}

Young male chicks of four days old weighing 25-35gms were purchased from the District Poultry Farm, near Khanikar Park, Dibrugarh. They are grouped and housed under a standard $12 \mathrm{hrs}$ light/dark cycle and in controlled conditions of temperature $\left(25 \pm 2^{\circ} \mathrm{C}\right)$ and humidity $(55 \pm 2 \%)$. The chicks were fed with properly balanced chick diet (chick crumb) and given free access to water for drinking.

\section{Preparation of extracts 5}

The plant materials were washed thoroughly with water to free from extraneous impurities if any and allowed to dry on a drier table at room temperature under shade for 2 weeks. The dried stems were then pulverized into fine powder in an electric mixer grinder and the powder was stored in airtight containers. Sufficient quantity of the powder (60 gms) was then subjected to extraction process with $300 \mathrm{ml}$ of $100 \%$ methanol using Soxhlet apparatus with the heating mantle set at $65^{\circ} \mathrm{C}$ (Figure 1). After a reflux of 3 hours, the mixture was filtered using a Muslin cloth and subsequently with filter paper to obtain a fine filtrate. The filtrate was evaporated for a few hours to remove the residual methanol using a water-bath at $65^{\circ} \mathrm{C}$. A brownish paste like material was obtained which was collected in glass petri dishes (Figure 2). The extract material is then subjected to vacuum desiccation.

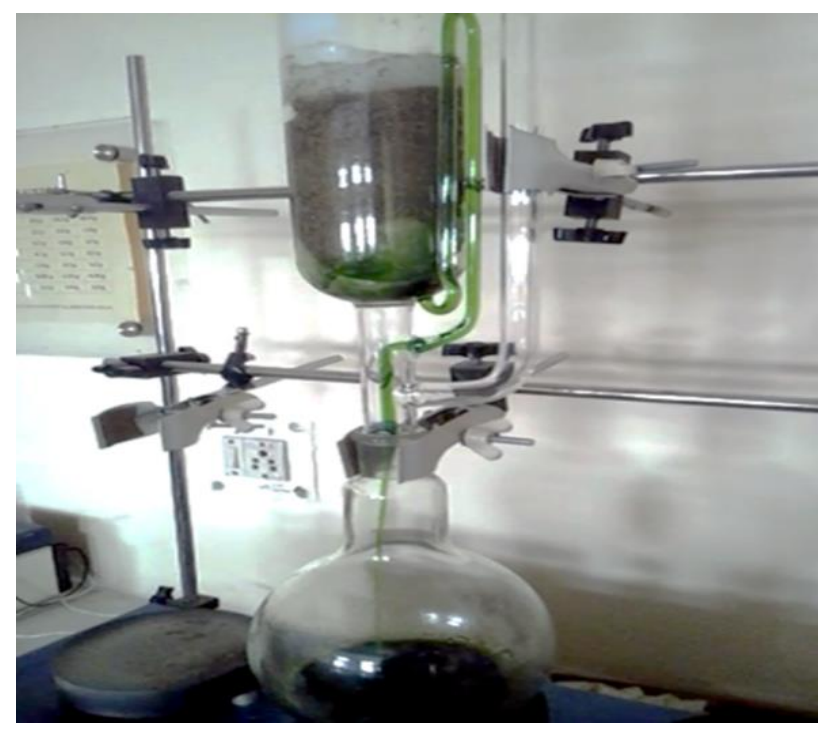

Figure 1: Soxhlet extraction for the extract.

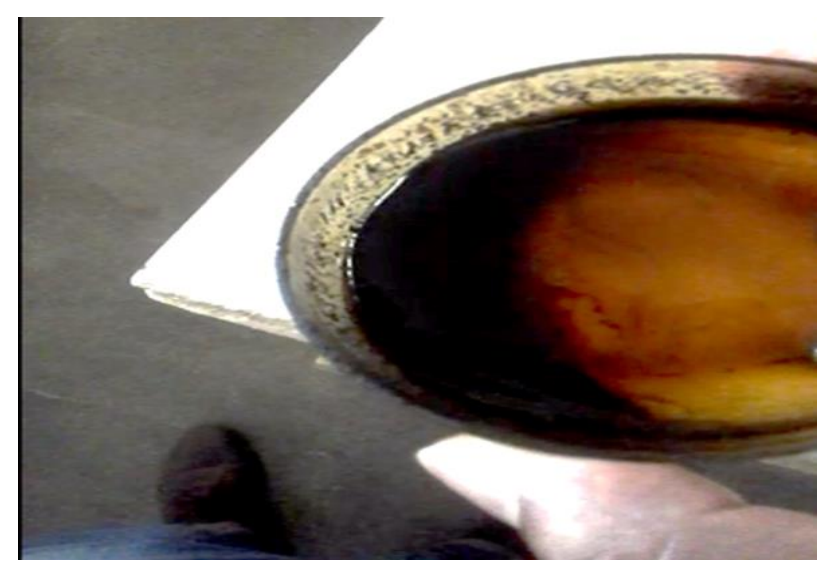

Figure 2: Brown paste like extract. 
The same process of extraction was repeated for another 3 times with $60 \mathrm{gms}$ powder each time. Properly dried and thickened extract was obtained weighing $47.68 \mathrm{gms}$ i.e. $19.78 \%$ (w/w) yield with respect to the original air-dried powder. The extract was sealed in an airtight container, labelled and stored at $4^{\circ} \mathrm{C}$.

\section{Acute oral toxicity study ${ }^{6}$}

Acute oral toxicity test for the extract was carried out as per the OECD (Organization for Economic Cooperation and Development) Guidelines 425. The extract was found safe even at doses more than $2000 \mathrm{mg} / \mathrm{kg}$ without any sign of toxicity or mortality and arbitrary doses of $50 \mathrm{mg}$, $100 \mathrm{mg}$ and $150 \mathrm{mg} / \mathrm{kg}$ body weight were chosen for the study.

\section{Phytochemical analysis ${ }^{7}$}

Preliminary qualitative phytochemical screening was done to detect the presence of common phytoconstituents according to the standard procedure mentioned below:

\section{Detection of alkaloids (Wagner's test)}

Extract was dissolved in dilute hydrochloric acid and filtered. Filtrate was treated with Wagner's reagent (Iodine in Potassium Iodide). Formation of a brown or reddish precipitate would indicate the presence of alkaloids.

\section{Detection of glycosides (Modified Borntrager's test)}

Extract was hydrolysed with dilute hydrochloric acid and then subjected to ferric chloride solution. After that it was immersed in boiling water for about 5minutes. The mixture was cooled and extracted with equal volumes of benzene. The benzene layer was separated and treated with ammonia solution. Formation of a rose-pink colour in ammonical layer would indicate the presence of anthranol glycosides.

\section{Detection of tannins (Gelatin test)}

About $1 \%$ gelatin solution containing sodium chloride was added to the extract. Formation of a white precipitate would indicate the presence of tannins.

\section{Detection of saponins (Froth test)}

Extract was diluted with distilled water to $20 \mathrm{ml}$ and was shaken in a graduated cylinder for 15 minutes. Formation of a $1 \mathrm{~cm}$ layer of foam would indicate the presence saponins.

\section{Detection of phenols (Ferric chloride test)}

Extract was treated with 4 drops of ferric chloride solution. Formation of a bluish black color would indicate the presence of phenols.

\section{Detection of flavonoids (Alkaline reagent test)}

Extract was treated with few drops of sodium hydroxide solution. Formation of an intense yellow color that would become colourless on addition of dilute acid, would indicate presence of flavonoids.

\section{Detection of triterpenes (Salkowski's test)}

Extract was treated with chloroform and filtered. The filtrate was treated with few drops of concentrated sulphuric acid and then shaken and allowed to stand. Appearance of a golden yellow colour would indicate presence of triterpenes.

\section{Detection of diterpenes (Copper acetate test)}

Extract was dissolved in water and treated with 4 drops of copper acetate solution. Formation of an emerald green colour would indicate the presence of diterpenes.

\section{Experimental design}

The antiemetic activity was evaluated as per the protocol of Akita Y et al, $1998 .{ }^{8}$ The chicks were grouped into 5 with each group bearing 5 chicks $(n=5)$. After a period of fasting of $24 \mathrm{hrs}$, the chicks were brought to the laboratory on the day of the experiment. The experiment was carried out from 9 O'clock in the morning in an ambient and noise free environment. All the chicks were set aside in a large beaker at $380^{\circ} \mathrm{C}$ for 10 minutes to stabilize them. After that, the drugs were administered as per the groups shown below:

- Group I (control): normal saline $10 \mathrm{ml} / \mathrm{kg}$ body weight intraperitoneally (i.p)

- Group II (standard): chlorpromazine $150 \mathrm{mg} / \mathrm{kg}$ body weight (i.p)

- Group III (experimental-1): MESSC at $50 \mathrm{mg} / \mathrm{kg}$ body weight (i.p)

- Group IV (experimental-2): MESSC at $100 \mathrm{mg} / \mathrm{kg}$ body weight (i.p)

- Group V (experimental-3): MESSC at $150 \mathrm{mg} / \mathrm{kg}$ body weight (i.p)

- (MESSC: Methanolic Extract from stems of Swertia chirata).

Chlorpromazine and the MESSC were prepared as solutions in $0.9 \%$ saline containing $5 \%$ DMSO and $1 \%$ Tween 80 and were injected intraperitoneally at the volume of $10 \mathrm{ml} / \mathrm{kg}$ body weight in doses as shown above. After injection, we waited for 10minutes and each group was fed copper sulfate anhydride orally at the dose of $50 \mathrm{mg} / \mathrm{kg}$ body weight.

Assessment of anti-emesis: Next to feeding of copper sulfate, was to observe the number of retches for 10 minutes. Retch is an episode of an emetic action without actual vomiting of gastric contents. After that the 
percentage of inhibition of retching was calculated according to the formula:

$\%$ inhibition $=(\mathrm{A}-\mathrm{B}) / \mathrm{A} \times 100$

Where, $A=$ No. of retches in the control group (i.e. group I), $\mathrm{B}=$ No. of retches in the test group (i.e. groups II, III, IV, V).

\section{Statistical analysis}

All the values are expressed as Mean \pm SEM (Standard Error of Mean).

The data were statistically analysed by using one-way ANOVA followed by post hoc analysis which was done by Bonferroni's test.9 P-value <0.05 was considered significant and $<0.001$ was considered as highly significant. All statistical analysis was done by the software, GraphPad Prism 5.

\section{RESULTS}

\section{Phytochemical analysis of MESSC}

Phytochemical analysis MESSC of (methanolic extract from the stems of Swertia chirata) revealed the following:

Detection of alkaloids (Wagner's test)

A reddish precipitate was seen that indicated the presence of alkaloids.

\section{Detection of glycosides (Modified Borntrager's test)}

A rose-pink colour in ammonical layer was seen that indicated the presence of anthranol glycosides.

\section{Detection of tannins (Gelatin test)}

No white precipitate was seen that indicated the absence of tannins.

\section{Detection of saponins (Froth test)}

No $1 \mathrm{~cm}$ layer of foam was found that indicated the absence of saponins.

\section{Detection of phenols (Ferric chloride test)}

No bluish black color was seen that indicated the absence of phenols.

\section{Detection of flavonoids (Alkaline reagent test)}

An intense yellow color was seen that became colourless on addition of a dilute acid. It indicated presence of flavonoids.

\section{Detection of triterpenes (Salkowski's test)}

A golden yellow colour appeared that indicated presence of triterpenes.

\section{Detection of diterpenes (Copper acetate test)}

An emerald green colour was seen that indicated the presence of diterpenes.

So, the phytochemical analysis revealed the presence of alkaloids, glycosides, flavonoids, triterpenes and diterpenes. Whereas the presence of tannin, saponin and phenol could not be detected in the extract (Table 1).

\section{Results of antiemetic activity}

All the three doses of the extract i. e. 50mg, 100mg and $150 \mathrm{mg}$ per $\mathrm{kg}$ body weight showed antiemetic activities. The dose of $50 \mathrm{mg} / \mathrm{kg}$ body wt. showed activity $(42.22 \%$ inhibition) comparable to chlorpromazine $(44.44 \%$ inhibition), whereas the doses of $100 \mathrm{mg} / \mathrm{kg}$ body wt. and $150 \mathrm{mg} / \mathrm{kg}$ body wt. showed activity higher than that of chlorpromazine $\quad(77.78 \%$ and $79.26 \%$ inhibition, respectively. Highest antiemetic activity was shown by the extract at dose of $150 \mathrm{mg} / \mathrm{kg}$ body wt. whereas lowest activity was shown by $50 \mathrm{mg} / \mathrm{kg}$ body wt. (Table 2 , Figure 3).

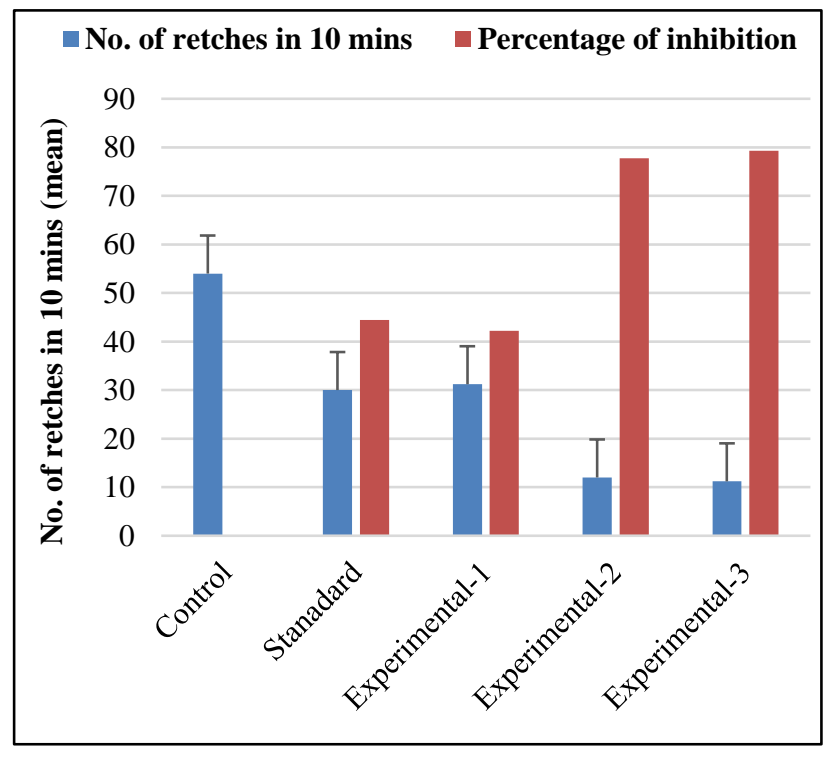

Figure 3: Bar diagram (clustered columns) showing the comparison between different

treatment groups in terms of no. of retches in $10 \mathrm{mins}$ and percentage of inhibition.

The P-value of group III (experimental-1) receiving extract at $50 \mathrm{mg} / \mathrm{kg}$ body wt. was greater than 0.05 when compared to group II (standard) receiving chlorpromazine at $150 \mathrm{mg} / \mathrm{kg}$ body wt. which was non-significant P-value. 
On the other hand, both group IV (experimental-2) receiving extract at $100 \mathrm{mg} / \mathrm{kg}$ body wt. and group V (experimental-3) receiving the extract at $150 \mathrm{mg} / \mathrm{kg}$ body wt. had P-values less than 0.001 (highly significant value) when compared with the group II. It is also important to see that the mean difference between the values of group IV and group $\mathrm{V}$ was non-significant, whereas both values were significant when compared with group III (Table 2).

Table 1: Results of phytochemical analysis of MESSC*.

\begin{tabular}{|llll|}
\hline Class & Test & Observation & Result \\
\hline Alkaloid & Wagner's test & Yellow precipitate & Positive \\
\hline Glycoside & Modified Borntrager's test & Rose-pink colour in ammonical layer & Positive \\
\hline Tannin & Gelatin test & No precipitate & Negative \\
\hline Saponin & Froth test & No froth & Negative \\
\hline Phenol & Ferric chloride test & No bluish black colour & Negative \\
\hline Flavonoid & Alkaline reagent test & $\begin{array}{l}\text { Intense yellow colour appears that fades off on } \\
\text { addition of dilute acid }\end{array}$ & Positive \\
\hline Triterpenes & Salkowski's test & Golden yellow colour & Positive \\
\hline Diterpenes & Copper acetate test & Emerald green colour & Positive \\
\hline
\end{tabular}

(*MESSC : Methanolic Extract from Stems of Swertia chirata)

Table 2: Results of antiemetic activity.

\begin{tabular}{|c|c|c|c|}
\hline Groups & No. of animals & $\begin{array}{l}\text { Number of retches in } \mathbf{1 0} \text { mins } \\
\left(\text { Mean } \pm \text { S.E.M }{ }^{*}\right)\end{array}$ & $\%$ inhibition of retches \\
\hline I (control) & 5 & $54 \pm 3.082$ & \\
\hline II (standard) & 5 & $30 \pm 1.000$ & $44.44 \%$ \\
\hline III (experimental-1) & 5 & $31.20 \pm 1.715^{\mathrm{a}}$ & $42.22 \%$ \\
\hline IV (experimental-2) & 5 & $12 \pm 0.7071^{\mathrm{bcd}}$ & $77.78 \%$ \\
\hline V (experimental-3) & 5 & $11.20 \pm 1.200^{\mathrm{bcd}}$ & $79.26 \%$ \\
\hline \multirow{2}{*}{ One-way ANOVA** } & $\mathrm{F}^{* *}$ & 82.10 & \\
\hline & $\mathrm{df}^{* * *}$ & 19 & \\
\hline
\end{tabular}

*S.E.M = Standard Error of Mean. Values are expressed as Mean \pm S.E.M ( $\mathrm{n}=5)$. One-way ANOVA followed by Bonferroni's test was done between the groups. $\mathrm{P}<0.05$ was considered significant and $\mathrm{P}<0.001$ was considered highly significant. $\mathrm{P}^{\mathrm{a}}>0.05$ (non-significant) when compared with Standard. $\mathrm{P}^{\mathrm{b}}<0.001$ when compared with standard. $\mathrm{P}^{\mathrm{c}}<0.001$ when compared with group III (Experimental-1). $\mathrm{P}^{\mathrm{d}}>0.05$ when compared between group IV (experimental-2) and group V (experimental-3). **ANOVA= Analysis of Variance; $\mathrm{F}=$ Fisher's factor; $\mathrm{df}=$ degrees of freedom.

\section{DISCUSSION}

From the results obtained, it may be interpreted that all the three doses of the extract from Swertia chirata, possessed antiemetic activity, with one dose at $50 \mathrm{mg} / \mathrm{kg}$ body wt. having activity comparable to chlorpromazine \& with two doses at $100 \mathrm{mg} / \mathrm{kg}$ body wt. and $150 \mathrm{mg} / \mathrm{kg}$ body wt. having activity greater than chlorpromazine. Highest anti-emetic activity (79.26\% inhibition) was shown by the extract at the dose of $150 \mathrm{mg} / \mathrm{kg}$ body wt. and lowest $(42.22 \%)$ at the dose of $50 \mathrm{mg} / \mathrm{kg}$ body wt.

The results were highly significant $(\mathrm{P}<0.001)$ for doses at $100 \mathrm{mg}$ and $150 \mathrm{mg} / \mathrm{kg}$ body wt. It is important to note that the antiemetic activity of the extract was not significant at low dose $(50 \mathrm{mg} / \mathrm{kg}$ body wt.) but highly significant at higher doses (100mg and $150 \mathrm{mg} / \mathrm{kg}$ body wt.). However, the mean difference in the activity in higher doses was not significant. These together showed that the antiemetic activity of the extract increases with dose only upto a certain extent and minor increase in dose increases the response to great extent.

Copper sulfate induces emesis by peripheral action through excitation of visceral afferent nerve fibres of the gastrointestinal $\operatorname{tract}^{10}$, and it has been reported that peripheral $5-\mathrm{HT}_{4}$ receptors play important role in emesis induced by copper sulfate. ${ }^{11,12}$ Studies have also shown that copper sulfate stimulates vagal afferents located in the G.I tract to induce emesis. ${ }^{13}$ Since all doses of the extract inhibited copper sulfate induced emesis, it can be implied that the extract had peripheral antiemetic action either by inhibition of $5-\mathrm{HT}_{4}$ receptor mediated emesis or by inhibition of local vagal inputs from G.I tract or both.

The role of tannin, saponin and phenol in producing the antiemetic action of the extract can be excluded because these were found absent in the extract. However, presence 
of alkaloids, glycosides, flavonoids and terpenes in the extract predicted the role of one or more of these chemicals in producing the antiemetic activity. Further studies regarding the identification of specific active compound and toxicological analysis in higher animals are required to further validate the role of Swertia chirata extract in antiemesis.

\section{ACKNOWLEDGEMENTS}

Authors would like to express their sincere gratitude to all the laboratory staff, specially Sri Bipul Thakuria, laboratory technician in the Department of Pharmacology, Assam Medical College, Dibrugarh for his constant support in carrying out the experiment.

Funding: No funding sources Conflict of interest: None declared

Ethical approval: The study was approved by the Institutional Animal Ethics Committee (IAEC) of Assam Medical College, Dibrugarh, Assam, India

\section{REFERENCES}

1. Greenberger N. Nausea and Vomiting in Adults. www.msdmanuals.com. 2018. Available at: https://www.msdmanuals.com/home/digestivedisorders/symptoms-of-digestive-disorders/nauseaand-vomiting-in-adults. Accessed 22 August 2018.

2. Kumar V, Van Staden J. A Review of Swertia chirayita (Gentianaceae) as a traditional medicinal Plant. Front Pharmacol. 2016;6:308.

3. Singh R, Singh P, Agarwal A. Chemical constituents and bio-pharmacological activities of Swertia chirata: A review. NPAIJ. 2012;8(6):238-47.

4. Tabassum S, Mahmood S, Hanif J, Hina M, Uzair B. An overview of medicinal importance of Swertia chirayita. Int J f App Sci Technol. 2012;2(1):298-304.

5. Saidu AN, Abubakar AN, Daniel MU, Kabiru AY. Phytochemical Screening and Effects of Methanolic Extract of Azadirachta Indica Leaf in Alloxan Induced Diabetic Rats. IOSR J Pharma Biol Sci. 2014;9(1):1620.
6. OECD (Organization for Economic Cooperation and Development) guidelines for testing chemicals. France: OECD publishing; 2006 July 11, Section 4, health effects; test no.425; Acute oral toxicity; Up and down procedure:1-27. Available at: http://iccvam.neihs.nih.gov/SuppDocs/FedDocs/OEC D /OECDtg425.pdf. Accessed 22 August 2018.

7. Tiwari P, Kumar B, Kaur M, Kaur G, Kaur H. Phytochemical screening and Extraction: A Review. Inte Pharmaceut Sci. 2011;1(1):98-106.

8. Akita Y, Yang Y, Kawai T, Kinoshita K, Koyama K, Takahashi $\mathrm{K}$ et al. New assay method for surveying anti-emetic compounds from natural sources. Natural Product Sci. 1998;4(2):72-7.

9. Bretz F, Westfall P, Hothorn T. Multiple comparisons using R. Boca Raton: Chapman \& Hall/CRC. 2011:31.

10. Reddy R, Kumar B, Bakshi V. Phytochemical screening and antiemetic activity of Lepidagatis cristata root extract. IJRPP. 2014;3(4):269-72.

11. Bulbul L, Uddin M, Sushanta S, Tanni S, Nipa A, Baul S. Phytochemial investigation and evaluation of antiemetic and anthelmintic activities of Polygonum lapathifolium roots extract. Int $\mathbf{J}$ of Pharm Life Sci. 2013;4(5):2632-7.

12. Nakayama $H$, Yamakuni $H$, Higaki $M$, Ishikawa $H$, Imazumi K, Matsuo M, et al. Antiemetic Activity of FK1052, a 5-HT3- and 5-HT4-Receptor Antagonist, in Suncus murinus and Ferrets. J Pharmacol Sci. 2005;98:396-403.

13. Horn CC, Meyers K, Lim A, Dye M, Pak D, Rinaman L, Yates BJ. Delineation of vagal emetic pathways: intragastric copper sulfate-induced emesis and viral tract tracing in musk shrews. Am J Physiol Regul Integr Comp Physiol. 2014 Jan 15;306(5):R341-51.

Cite this article as: Medhi PK, Gohain K, Study on the antiemetic property of methanolic stem extract of Swertia chirata using chick emesis model. Int J Basic Clin Pharmacol 2019;8:327-32. 